\title{
Student Perceptions of a Basic Medical Science-focused Advanced Pharmacy Practice
} Experience

\author{
Marilyn E. Thompson, Ph.D., Ken Reed, Ph.D., Kendall Schultes Pharm.D. ${ }^{1}$, Cathy \\ Ficzere, PharmD.,BCPS \\ Belmont University College of Pharmacy \\ 1900 Belmont Blvd. \\ Nashville, TN 37221 \\ United States
}

marilyn.odom@belmont.edu

ken.reed@belmont.edu

cathy.ficzere@belmont.edu

Kendall.shultes@bjc.org

Corresponding author:

Marilyn E. Thompson, Ph.D.

1900 Belmont Blvd.

College of Pharmacy

Belmont University

McWhorter 320

Nashville, TN 37212

(615) 460-8121

\section{${ }^{1}$ Current address}

Barnes-Jewish Hospital

Mailstop 90-52-411

216 S. Kingshighway Blvd.

St. Louis, MO 63110 


\begin{abstract}
Aims

The four-year Doctor of Pharmacy curriculum at Belmont University College of Pharmacy requires student pharmacist to successfully complete 10 -one month rotations in clinical or research facilities. Basic science faculty offer rotations which expose student pharmacists to basic medical bench research. The objectives of this study were to (1) evaluate the student pharmacists' assessments of the facilities, preceptor, and experiences during the rotation, and (2) assess student phamacists' perceptions as described in their reflections.
\end{abstract}

\title{
Methods
}

Student perception of the rotation was measured in two ways. First, an Educator Evaluation was conducted through $\mathrm{E}^{*}$ Value ${ }^{\mathrm{TM}}$. The instrument was divided into Section I which queried about the site/experience and Section II which focused on the preceptor. Second, investigators reviewed student pharmacists' reflections using narrative and content analysis to evaluate how students expressed their feelings regarding the APPE. Key topics were defined according to reported findings and elective research rotation supportive rationale. A pair-wise linear regression was performed on data.

\section{Results}

Student pharmacists rated the laboratory facilities and the preceptors highly. Through reflective exercises, student pharmacists expressed a high level of satisfaction with the research rotations. A comparison of results from two independent investigators searching the reflections for key terms relating to the outcome of the rotation showed a strong correlation between the results from each individual investigator.

\section{Final conclusions}

This rotation may not be appropriate for all student pharmacists; however, for those with an interest in research, the rotation can provide an opportunity to further explore the area. This helps to enhance certain characteristics, such as data interpretation and critical thinking skills. Overall, students felt that the rotation benefited them as future pharmacists.

Key Words: advanced pharmacy practice experience, bench research, reflections, critical thinking 


\subsection{Introduction/Background}

Basic science research is the foundation of medical advancement. These advancements have led to concepts such as pharmacogenomics and personalized medicine. As medical advances continue to evolve, it will be necessary for the role of the pharmacist, as a medication expert, to evolve similarly. This need became clearly evident in 2006 when the National Institutes of Health convened a special conference, "Pharm.D. Pathways in Biomedical Research," to discuss training of pharmacy researchers. ${ }^{3}$ Included within the conference recommendations was for schools of pharmacy to promote pharmacy research experiences for student pharmacists. ${ }^{3}$ As such, it should be beneficial for the curriculum of Doctor of Pharmacy (Pharm.D.) programs to include a mechanism by which student pharmacists can obtain an understanding of basic science research and its roles in medical and pharmaceutical advancement.

The inclusion of basic medical research within the Pharm.D. curriculum can serve several functions in the professional development of a student pharmacist. First, basic medical research can teach the concept of bench to bedside. Allowing student involvement at the earliest stage of drug development can help increase the understanding of the dynamic process that occurs during the development of a new drug to the final medication about which they counsel patients. Student pharmacists should also develop an appreciation for the time and efforts involved in the research process.

Second, basic medical research can provide opportunities for student pharmacists to develop skills to formulate a hypothesis and design and execute experiments to test their hypothesis. Discussion and critical review of the experimental results along with the formulation of conclusions can promote student understanding of the intricacies of drug development. These inquiry-based activities can also promote professional responsibility and create a sense of ownership for patient care. ${ }^{5}$

Third, research opportunities are venues through which students can strengthen their problem solving and critical thinking skills. The research process involves identifying problems and possible solutions while exploring various avenues to arrive at the best outcome. This thought process can then be applied to solving problems associated with patient care.

Finally, the incorporation of basic medical research within the pharmacy curricula can help prepare student pharmacists pursuing post-graduate residencies in clinical pharmacy. The American Society of Health-System Pharmacists (ASHP) accredited pharmacy residency programs require the educational outcome of demonstrating project management skills in a topic significant to pharmacy practice. These same standards require that residents conduct pharmacy practice research. These projects in post-graduate work require institutional review board approval, development of protocols and procedures, and scientific writing. ${ }^{6}$ Being exposed prior to post-graduate training to the inquisitive nature of medical research can prepare student pharmacists with the necessary skill set to excel at these projects.

The curriculum of many Pharm.D. programs include courses in biostatistics, drug information, and literature evaluation. When colleges of pharmacy were surveyed in May 2006, results indicated that coursework in statistics was required in $91 \%$ of the colleges and drug information/literature evaluation required in $94 \% .^{7}$ These skills, however, are of limited use without a thorough understanding of the research process. ${ }^{5}$

Belmont University is a liberal arts university located in Nashville, Tennessee, U.S. The four-year Doctor of Pharmacy program at Belmont University College of Pharmacy has a class size of approximately 75 student pharmacists, providing a student to faculty ratio of 10:1, 
allowing for personalized career development. Student pharmacists declare an academic concentration during the second year of the program in one of four areas: pharmacotherapy, information management, pharmacy management, and missions/public health. With this chosen concentration, student pharmacists fulfill graduation requirements while aligning their electives within their respective concentration. During the fourth year of the curriculum, student pharmacists complete 10 one-month rotations in various clinical or scientific settings. Advanced Pharmacy Practice Experiences (APPEs) in basic science laboratories were first offered in 2012. Our study aims to explore student pharmacists' perceptions on the basic medical bench research experience as part of the Pharm.D. curriculum. The results are based on analysis of student pharmacists' evaluations and reflections on their APPE research experience.

The APPEs evaluated in this report were developed to provide fourth year pharmacy students with foundational knowledge regarding basic pharmaceutical or medical research. This included introducing students to various approaches to designing and conducting qualitative and quantitative research projects. This rotation is unique in our institution, as all other APPE experiences occur at clinical sites. The objectives of this study were to (1) evaluate the student pharmacists' assessments of the facilities, preceptor, and experiences during the rotation, and (2) assess student pharmacists' perceptions as described in their reflections. Here, we report the results of this study which indicate that the student pharmacists felt the rotation enhanced their professional development in multiple ways.

\subsection{Materials and Methods}

Two faculty members from the Department of Pharmaceutical, Social, and Administrative Sciences developed a one-month research-focused APPE specific to their individual research interest. The APPE was designed with the goal of exposing fourth year Pharm.D. students to bench research in pharmaceutical or basic medical research. All student pharmacists were informed of these opportunities during the second semester of the third year prior to selection of APPE rotations. Student pharmacists then sought out the faculty member whose area of research was of interest to them and upon mutual agreement, the student was enrolled in that APPE elective. Selection for this rotation falls outside of the typical lottery system used to assign core APPEs. As faculty members' primary responsibility during the ninemonth academic year is to teach, these rotations were offered during May-July.

During the APPE, students worked an average of 7.5 hours per day for five days per week for one month. Faculty worked directly with the student pharmacists allowing for more independence as experience was gained. Students conducted bench research, including developing their hypothesis and aims to address the hypothesis. Weekly journal clubs were also presented and students were required to write reflective narratives during and after the rotation.

Student pharmacists received both formative and summative evaluations. Formative assessments were performed by the preceptor via feedback based on individual assignment performance criteria and a midterm evaluation based on the course performance objectives. Summative evaluations were completed at the end of the experience. Students were also required to complete an evaluation of the rotation and preceptor. Evaluations were conducted online through $\mathrm{E}^{*}$ Value ${ }^{\mathrm{TM}}$. 


\subsection{Data Collection and Evaluation}

Student perception of the course was measured by two instruments. First, an Educator Evaluation was conducted through $\mathrm{E}^{*} \mathrm{Value}^{\mathrm{TM}}$. The instrument was divided into Section I which queried about the site/experience and Section II which focused on the preceptor (Table 1). Students chose from 1 to 5 , where $1=$ strongly disagree; 2 = disagree; $3=$ neutral; $4=$ agree; $5=$ strongly agree. Not applicable was also a selection choice. Completion of the evaluation was mandatory.

Table 1: Evaluation Criteria Assessed by Students Through E-Value ${ }^{\text {TM }}$

\begin{tabular}{|l|}
\hline Category: Site/Experience \\
\hline Adequate facilities (e.g. space, resources, computer/internet access, technology \\
\hline Meets professional standards \\
\hline Rotation activities involved students in activities that enhanced learning \\
\hline $\begin{array}{l}\text { The location was adequate based on the learning objectives and competencies I was } \\
\text { required to achieve }\end{array}$ \\
\hline Has adequate support staff \\
\hline Category: Preceptor \\
\hline Provided an orientation to the site \\
\hline Provided clear expectations at the beginning of the rotation \\
\hline Was available to address questions and problems \\
\hline Recognized my challenges in understanding new tasks and new information \\
\hline Clearly and logically presented and demonstrated new tasks and information \\
\hline Objectively observed my performance of tasks and other responsibilities \\
\hline Challenged me to think critically or solve problems independently \\
\hline Devoted sufficient time to my learning \\
\hline Motivated me to do my best work \\
\hline Utilized the course syllabus and objectives when planning daily activities \\
\hline Was a useful mentor during completion of my course projects \\
\hline Provided clear explanations during discussions \\
\hline Demonstrated effective communications with health professionals and staff \\
\hline Provided constructive feedback on skills and abilities throughout the experience \\
\hline Provided a verbal and written midpoint evaluation \\
\hline Evaluation of my performance was fair and objective \\
\hline Provided supporting reasons for the performance scores I received \\
\hline Exhibited professional demeanor \\
\hline Was a role model I plan to emulate \\
\hline Was accepting of opposing viewpoints \\
\hline Exhibited sound ethical decision making \\
\hline Adequate level of organization and structure \\
\hline Sufficient degree of challenge \\
\hline Ability to apply previously acquired knowledge from coursework \\
\hline Primary preceptor rating \\
\hline
\end{tabular}


Second, investigators reviewed student pharmacists' reflections using narrative and content analysis to evaluate how students expressed their feelings regarding the APPE. Key topics were defined according to reported findings and elective research rotation supportive rationale as previously reported. ${ }^{4-10}$ Thirty-five topics were chosen and each topic was sequentially numbered in order to provide differentiation. The investigators were able to obtain 15 reflections from six of the 12 student pharmacists from the Experiential Education office of the college. Two investigators independently searched the students' reflections for statements referring to the key topics. For example, each reflection was carefully reviewed to assess the number of students who mentioned that the rotation increased their ability to interpret and understand pharmaceutical research findings. Each time this was mentioned, it was considered a hit. The number of times a key topic was observed (number of hits) was divided by 30 , the number of total possible hits (15 reflections reviewed by two investigators) and then multiplied by 100 to give a frequency percentage for each topic.

In order to measure the agreement in observing the reflections, the total number of hits for each topic (as determined by each investigator) was plotted against each other. A pair-wise linear regression was performed using Microsoft Excel and a correlation coefficient determined.

\subsection{Results}

Collectively during the first and second year in which this rotation was offered, six student pharmacists rotated between the two faculty labs. Results from the Education Evaluation surveys of the students revealed a consistent level of agreement (agree or strongly agree) among them that the physical facilities were adequate, professional standards were met, the activities enhanced student learning, the location was adequate to achieve learning objectives and competencies, and there was adequate support staff.

Overall, student pharmacists rated preceptors highly, agreeing or strongly agreeing with each statement. There was unanimous consensus of strong agreement among the students in several areas. These topics were that the preceptor provided a site orientation, provided clear expectations at the beginning of the rotation, was available to address questions, recognized unique challenges in understanding new tasks and information, clearly and logically presented and demonstrated new tasks and information, challenged the students to think critically, provided clear explanations during discussions, exhibited professional demeanor, served as a role model to emulate, was accepting of opposing viewpoints, exhibited sound ethical decision making, and provided a sufficient degree of challenge. Of the remaining categories, students agreed or strongly agreed with the statements regarding sufficient time being devoted to student learning, motivating the student to do best work, feeling that evaluation of their performance was fair and objective, and that there was adequate level of organization and structure. Similar results were obtained in the area of providing constructive feedback on skills and abilities throughout the rotation, providing supporting reasons for performance score, and provision of a verbal and written midpoint evaluation.

Other areas measured included utilizing the course syllabus and objectives when planning daily activities, demonstrating effective communications with health professionals and staff, and the ability to apply previously acquired knowledge from coursework. Some student pharmacists felt these topics were not applicable. Consequently, these results were not comprehensive.

Through the reflective exercises, student pharmacists expressed their perception and feelings regarding the APPE. These reflective essays were analyzed for the frequency in which key topics were identified. The results of the analysis by two investigators, independently, are 
provided in Table 2. The topics most frequently identified (50\% of reflections) alluded to the idea that students were (1) able to better interpret and understand pharmaceutical research findings and (2) that the research rotation improved their ability to problem solve. Thirty-seven percent of the reflections indicated that the student pharmacists gained a better understanding of the research process. Additionally, these results reinforce that the implementation of a voluntary research APPE rotation resulted in student pharmacists gaining an appreciation and understanding of pharmacy research. The reflections also indicated that the student pharmacists improved their ability to solve problems as a result of the rotation. Although some students $(20 \%)$ identified that they can apply the scientific method to solve everyday problems, this was not reflected with the same frequency as seen for problem solving skills (50\%). These results suggest that performing a voluntary research APPE may be effective in improving overall thinking skills.

Table 2: Response frequency to elective research APPE topics in student reflections.

\begin{tabular}{|c|c|c|c|c|}
\hline Topic & Investigator One & Investigator Two & Total & \% Total Possible \\
\hline $\begin{array}{l}\text { 1. The time was well } \\
\text { spent doing data collection, } \\
\text { data analysis, and reporting } \\
\text { study results.* }\end{array}$ & 4 & 11 & 15 & $50 \%$ \\
\hline $\begin{array}{l}\text { 27. They are able to better } \\
\text { interpret and understand } \\
\text { pharmaceutical research } \\
\text { findings. }\end{array}$ & 9 & 6 & 15 & $50 \%$ \\
\hline $\begin{array}{l}\text { 33. The research rotation } \\
\text { improved their ability to } \\
\text { problem solve. }\end{array}$ & 8 & 7 & 15 & $50 \%$ \\
\hline $\begin{array}{l}\text { 31. The research rotation } \\
\text { improved their critical } \\
\text { thinking skills.* }\end{array}$ & 10 & 2 & 12 & $40 \%$ \\
\hline $\begin{array}{l}\text { 8. They have a better } \\
\text { understanding of the } \\
\text { research process. }\end{array}$ & 5 & 6 & 11 & $37 \%$ \\
\hline $\begin{array}{l}20 . \text { The research rotation } \\
\text { enhanced their professional } \\
\text { vitality. }\end{array}$ & 6 & 4 & 10 & $33 \%$ \\
\hline $\begin{array}{l}\text { 13. The experience of } \\
\text { performing research was } \\
\text { beneficial to them from a } \\
\text { professional standpoint. }\end{array}$ & 4 & 5 & 9 & $30 \%$ \\
\hline $\begin{array}{l}\text { 10. They are motivated to } \\
\text { perform research in their } \\
\text { future careers. }\end{array}$ & 4 & 3 & 7 & $23 \%$ \\
\hline $\begin{array}{l}\text { 9. That they now can } \\
\text { apply the scientific method } \\
\text { to solve everyday problems. }\end{array}$ & 3 & 3 & 6 & $20 \%$ \\
\hline
\end{tabular}




\begin{tabular}{|c|c|c|c|c|}
\hline $\begin{array}{l}\text { 32. The research rotation } \\
\text { improved their ability to use } \\
\text { the literature. }\end{array}$ & 2 & 4 & 6 & $20 \%$ \\
\hline $\begin{array}{l}\text { 17. Sufficient time was not } \\
\text { allowed. }\end{array}$ & 2 & 1 & 3 & $10 \%$ \\
\hline $\begin{array}{l}\text { 23. Their education has } \\
\text { been made more complete. }\end{array}$ & 2 & 1 & 3 & $10 \%$ \\
\hline $\begin{array}{l}\text { 24. They are more } \\
\text { interested in continuing } \\
\text { their education. }\end{array}$ & 1 & 2 & 3 & $10 \%$ \\
\hline $\begin{array}{l}\text { 26. They are more } \\
\text { interested in pursuing a } \\
\text { career in pharmaceutical } \\
\text { research. }\end{array}$ & 1 & 2 & 3 & $10 \%$ \\
\hline $\begin{array}{l}\text { 28. They believe that they } \\
\text { are better prepared for a } \\
\text { possible residency position. }\end{array}$ & 2 & 1 & 3 & $10 \%$ \\
\hline $\begin{array}{l}\text { 35. They better understand } \\
\text { the need for professional } \\
\text { responsibility in performing } \\
\text { pharmaceutical research. }\end{array}$ & 3 & 0 & 3 & $10 \%$ \\
\hline $\begin{array}{l}\text { 16. Sufficient time was } \\
\text { allowed. }\end{array}$ & 1 & 1 & 2 & $7 \%$ \\
\hline $\begin{array}{l}\text { 29. They are differentiated } \\
\text { from other candidates for } \\
\text { residency positions. }\end{array}$ & 1 & 1 & 2 & $7 \%$ \\
\hline $\begin{array}{l}\text { 34. They are better self- } \\
\text { directed learners. }\end{array}$ & 1 & 1 & 2 & $7 \%$ \\
\hline $\begin{array}{l}\text { 11. They are now better } \\
\text { able to explain } \\
\text { pharmaceutical research } \\
\text { findings to patients and/or } \\
\text { customers. }\end{array}$ & 1 & 0 & 1 & $3 \%$ \\
\hline $\begin{array}{l}\text { 18. Generating a paper } \\
\text { would have been beneficial }\end{array}$ & 0 & 1 & 1 & $3 \%$ \\
\hline $\begin{array}{l}\text { 21. The research rotation } \\
\text { enhanced their capability to } \\
\text { deal with changes in clinical } \\
\text { science. }\end{array}$ & 0 & 1 & 1 & $3 \%$ \\
\hline $\begin{array}{l}\text { 22. The research rotation } \\
\text { enhanced their capability to } \\
\text { deal with changes in } \\
\text { pharmacy practice }\end{array}$ & 1 & 0 & 1 & $3 \%$ \\
\hline $\begin{array}{l}\text { A complete research } \\
\text { project should be required } \\
\text { for only select students. }\end{array}$ & 0 & 0 & 0 & $0 \%$ \\
\hline
\end{tabular}




\begin{tabular}{|c|c|c|c|c|}
\hline $\begin{array}{l}\text { 3. A complete research } \\
\text { project should be required } \\
\text { for most students. }\end{array}$ & 0 & 0 & 0 & $0 \%$ \\
\hline $\begin{array}{l}\text { 4. A complete research } \\
\text { project should be required } \\
\text { for all students. }\end{array}$ & 0 & 0 & 0 & $0 \%$ \\
\hline $\begin{array}{l}\text { 5. A complete research } \\
\text { project should be available } \\
\text { for only select students. }\end{array}$ & 0 & 0 & 0 & $0 \%$ \\
\hline $\begin{array}{l}\text { 6. A complete research } \\
\text { project should be available } \\
\text { for most students. }\end{array}$ & 0 & 0 & 0 & $0 \%$ \\
\hline $\begin{array}{l}\text { 7. A complete research } \\
\text { project should be available } \\
\text { for all students. }\end{array}$ & 0 & 0 & 0 & $0 \%$ \\
\hline $\begin{array}{l}\text { 12. They are now better } \\
\text { able to explain } \\
\text { pharmaceutical research } \\
\text { findings to professional } \\
\text { colleagues. }\end{array}$ & 0 & 0 & 0 & $0 \%$ \\
\hline $\begin{array}{l}\text { 14. It would be more } \\
\text { beneficial to have } \\
\text { conducted this research as } \\
\text { part of a fellowship } \\
\text { program. }\end{array}$ & 0 & 0 & 0 & $0 \%$ \\
\hline $\begin{array}{l}15 . \text { It would be more } \\
\text { beneficial to have } \\
\text { conducted this research as } \\
\text { part of a MS or PhD } \\
\text { program. }\end{array}$ & 0 & 0 & 0 & $0 \%$ \\
\hline $\begin{array}{l}\text { 19. Generating a poster } \\
\text { was beneficial. }\end{array}$ & 0 & 0 & 0 & $0 \%$ \\
\hline $\begin{array}{l}25 . \text { They are more } \\
\text { interested in pursuing an } \\
\text { academic career in } \\
\text { pharmacy. }\end{array}$ & 0 & 0 & 0 & $0 \%$ \\
\hline $\begin{array}{l}\text { 30. They are differentiated } \\
\text { from other candidates for } \\
\text { pharmacy positions. }\end{array}$ & 0 & 0 & 0 & $0 \%$ \\
\hline
\end{tabular}

*Topics with low level of agreement between two independent investigators.

Some reflections indicated satisfaction with a laboratory research experience. Their professional vitality was enhanced (33\%) and they also felt that performing research was of professional benefit (30\%). They were motivated to perform research in the future (23\%). A small percentage of the reflections indicated that student pharmacists believed that their education was more complete $(10 \%)$ and that they are better able to use scientific literature 
(20\%). Some indication was given that the student pharmacists felt that they were better prepared and differentiated for residencies $(10 \%)$ than their counterparts who did not participate in similar rotations.

In order to measure the agreement in observing the reflections, the total number of hits for each topic (as determined by the two independent investigators) was plotted against each other (Figure 1). A pair-wise linear regression and a Pearson's correlation coefficient of $0.68\left(\mathrm{r}^{2}\right.$ of .47) was obtained. This is indicative of a good relationship between how the two investigators independently rated the frequency (hits) at which topics were identified in the reflections ${ }^{2}$. Additionally, the relationship is considered to be statistically significant ( $\mathrm{p}$ value $<0.05$ ).

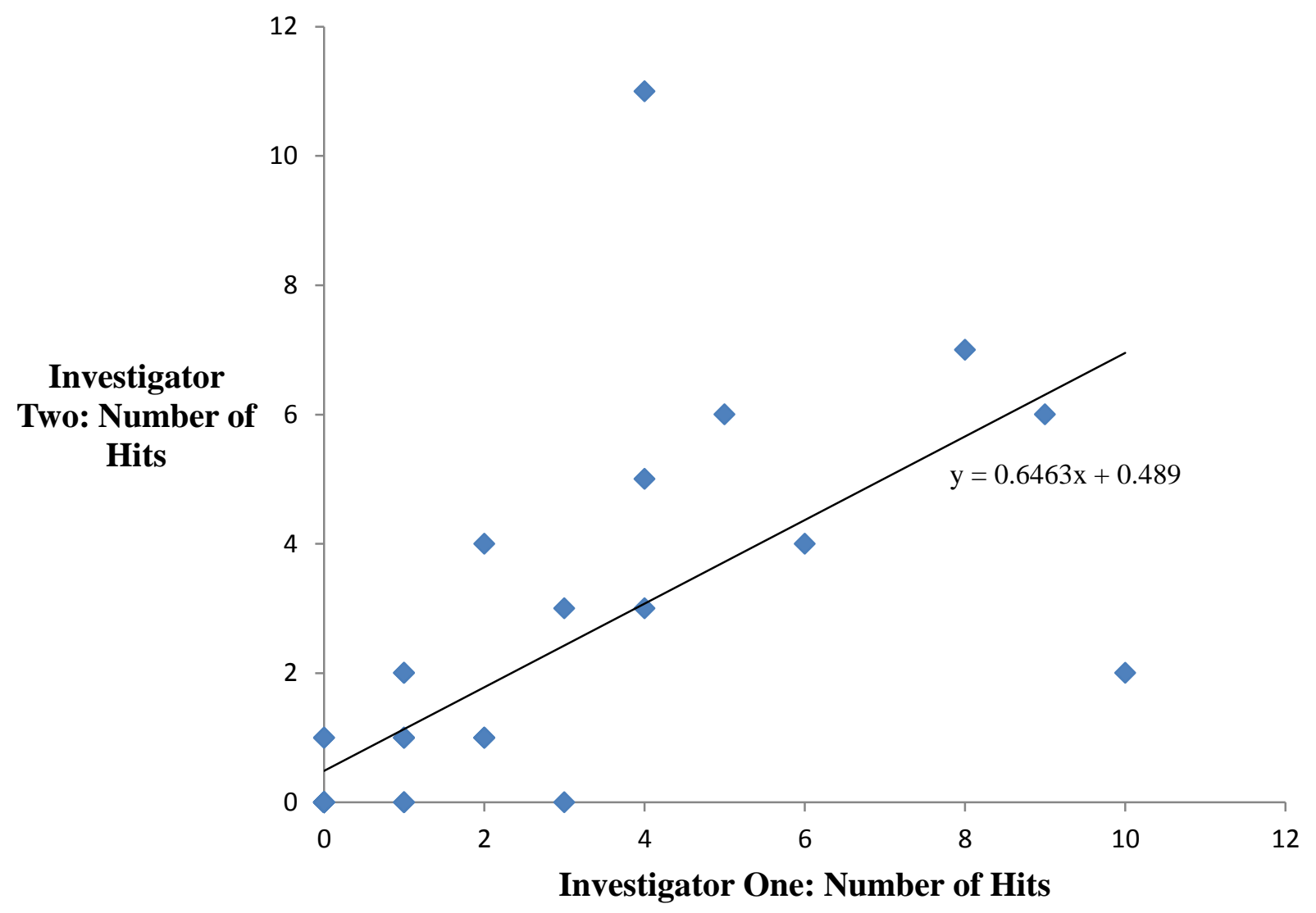

Figure 1: Correlation between total topic hits for independent investigators. The total number of hits as determined by each individual investigator was plotted against each other. A pairwise linear regression analysis was performed.

The two investigators strongly varied with each other regarding the idea that the time was well spent doing data collection, data analysis, and reporting study results. One investigator determined that there were four hits $(27 \%)$, whereas the second investigator found 11 hits (73\%). Although the investigators interpreted the students' reflective statements differently, they both found that the students believed that their time had been well spent. This is in agreement with the student survey findings in which students agreed or strongly agreed with the statements regarding sufficient time being devoted to student learning. 
The second topic in which the two investigators' results strongly varied from each other addressed whether the research rotations improved their critical thinking skills. Investigator one found a $67 \%$ hit rate compared to a $13 \%$ hit rate for investigator two. Thus, both investigators observed that the students believed their critical thinking skills had improved, but at different comment levels in their reflections. Student survey data indicated that the students had been challenged to think critically. It appears that the students did engage in critical thinking, but perhaps not to the level practiced in regard to problem solving. If the topic hit data were regressed with these two topics removed from the regression analysis (Figure 2), then a correlation coefficient of 0.89 was obtained.

The students' reflections did not indicate a change in career direction. There was no indication that the students were more interested in pursuing an academic career (topic 25) and little interest was shown in continuing their education as a result of performing lab research (topic 24). No hits were observed by the investigators for topics 2, 3, 4, 5, 6, and 7 which appear to indicate that the students believe the research experience was valuable for them personally, but it is not the right experience for all students.

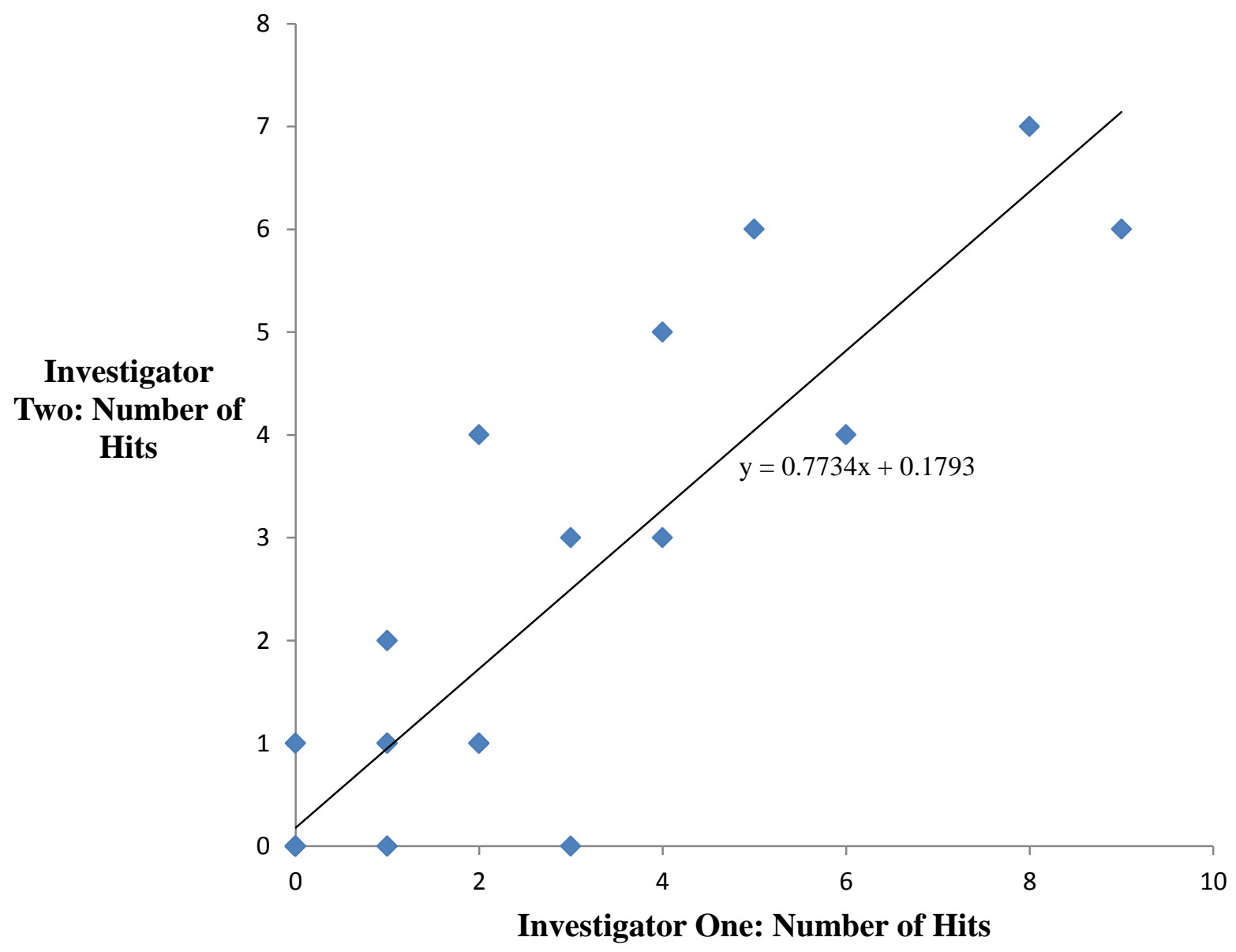


Figure 2. Topics 1 and 31 removed, correlation between total topic hits for independent investigators. Pairwise linear regression analysis was performed on the total number of hits for each investigator after topics 1 and 31 were excluded.

\subsection{Discussion}

A one-month research rotation totaling 150 hours was added to the electives offered in the Belmont University College of Pharmacy APPE curriculum in 2012. During this rotation, student pharmacists were required to develop a hypothesis and the specific aims to test the hypothesis, design and conduct experiments to carry out those aims, analyze the data, and draw conclusions based on the results. Through search of the literature, no articles describing a bench science APPE rotation were found. This may not indicate that these experiences are not or have not been offered; however, it does suggest the absence of a published critique of the rotations. Here we provide an assessment of basic medical research APPEs based on student pharmacists' evaluations and reflections.

A commission position paper from the American Association of Colleges of Pharmacy states that "part of the mission of pharmacy education is responsibility for generating and disseminating new knowledge about drugs, drug products, drug therapy, and drug use through the conduct of basic and applied research. ${ }^{4,9}$ Additionally, the American Society of Health System Pharmacists stated that "Pharmacists in organized health-care settings have a professional obligation to participate actively in and increase pharmacy-related and drug-related research efforts." ${ }^{.9}$ However, the opportunities for students to learn about basic research are limited. In a survey reported by Murphy, et al., ${ }^{6} 41.0 \%$ of surveyed Pharm.D. programs provided students the opportunity to conduct research as an elective offering in 1997. Only12.9\% of surveyed schools required an extensive research project with a project proposal, generation/interpretation of data, and presentation/defense of the findings. ${ }^{6}$ By 2007 , the number of schools offering research electives had increased to $57 \%{ }^{7}$. The primary issue interfering with offering a research experience has been identified as a lack of resources. More exactly, the lack of faculty time to mentor and oversee research projects was cited. ${ }^{7}$ This may explain the low number of schools offering an extensive research project in spite of the known benefits.

Based on results from student pharmacists' evaluations, the overall student experience during the bench research electives at our institution was positive. All students felt that the infrastructure supporting the research experiences was sufficient for their rotations. This included the physical facilities, as well as adjunct personnel. The strengths of the preceptors also allowed for a favorable experience by the students. These summative evaluations indicate that the resources, physical and human, are in place to provide beneficial research APPE electives.

The student pharmacists' reflective narratives also supported the implementation of these rotations. Throughout the rotations, students were required to write a reflection on their experience. Examining these essays for relevant topics revealed how students felt in regards to their research experience. The most frequently identified topics resonated around two themes. First, students felt that they had achieved a better understanding of bench research. Secondly, the rotations facilitated their problem solving skills.

Interestingly similar results as ours were obtained in a study conducted at Touro College of Pharmacy ${ }^{12}$. Investigators queried the value of student-driven research as a capstone experience. Students were required to engage in hypothesis-driven research in one of several areas, including basic science research. Student evaluations suggested the experience was 
successful, describing it as being "instructive". Students felt that the experience was beneficial for their career and benefits from the experience included enhancing critical thinking and problem-solving skills, as well as time management. Our results are similar in that many of our students felt their critical thinking and problem solving skills improved as a result of the experience. Likewise, they felt that the experience was important for them professionally. Thus, the APPE evaluated in this report yields similar student outcomes as a research capstone. With two different research formats demonstrating similar results, it appears that hypothesis-driven research enhances the professional development of student pharmacists and helps to prepare them for their career.

The preliminary results reported here suggest that this research elective falls within the scope of the 2016 Accreditation Committee for Pharmacy Education (ACPE) Standards. ${ }^{1}$ This document states that a research elective APPE must be "designed such that students are allowed to mature professionally, secure the breadth and depth of experience needed to achieve education outcomes articulated in standards 1- 4 and to explore selected sectors of practice". The APPE allows student pharmacists to broaden their thoughts on the research upon which drug design is based and improve problem solving abilities. These enhancements support professional maturation. Because these projects are biochemical and physical pharmacy in nature, the student pharmacist must utilize knowledge from the foundational sciences (Standard 1). The focus on the research interests of the faculty, ophthalmic diseases or breast cancer, allows the student pharmacists to increase their overall knowledge about these disease states. Therefore, the rotation is imparting knowledge to better provide patient-centered care and promoting health and wellness in these areas (Standard 2). The key elements within Standard 3 include problem solving, education, and communication. These qualities are fostered during the rotations. Likewise, key elements of Standard 4 such as self-awareness and professionalism are attained. Thus, the design and implementation of this APPE fall in line with ACPE guidelines.

\subsection{Conclusion}

This report describes the benefits of a basic medical science rotation in the Pharm.D.

curriculum. This rotation may not be appropriate for all student pharmacists as some do not have an interest in basic medical research; however, for those with an interest in research, the rotation can provide an opportunity to further explore the area. This will allow them to better understand how drug targets are discovered and/or how drug delivery processes are developed. Overall, student pharmacists perceived that these opportunities strengthened their professional development. 


\section{References}

1. Accreditation Council for Pharmacy Education. Accreditation Standards and Key Elements for the Professional Program in Pharmacy Leading to the Doctor of Pharmacy Degree. Chicago, IL: Accreditation Council for Pharmacy Education (2015). https://www.acpe-accredit.org/pdf/GuidanceforStandards2016FINAL.pdf

2. Colton, T. (1974). Statistics in Medicine. Boston, MA: Little, Brown and Company.

3. Figg, WD, Chau CH, Okita, R, Preusch P, Tracy TS, McLeod H, Reed M, Pieper J, Knoell, D, Miller, K, Speedie, M, Blouin R, Kroboth P, Koda-Kimble, MA, Taylor, P., Cohen, J, Giacomini, K. Pharm.D. Pathways to Biomedical Research: The National Institutes of Health Special Conference on Pharmacy Research. Pharmacotherapy 2008; 28 (7):821-833.

4. Hill LH, Delafuente JC, Sicat FL, Kirkwood CK. Development of a Competency-Based Assessment Process for Advanced Pharmacy Practice Experiences. Am. J Pharm Edu. 2006;70 (1):Article 01.

5. Jungnickel PW, Kelley KW, Hammer DP, Haines ST, Marlowe KF. Addressing competencies for the future in the professional curriculum. Am J Pharm Edu. 2009; 73 (8):156.

6. Murphy JE, Peralta LS, Kirking DM. Research experiences and research-related coursework in the education of doctor of pharmacy. Pharmacotherapy. 1999; 19 (2): 213220.

7. Murphy JE, Slack MK, Boesen KP, Kirking DM. Research-related coursework and research experiences in doctor of pharmacy programs. Am J Pharm Edu. 2007; 71(6): 113.

8. p D, Murphy JE, Marshall LL, Bell A. Pharmacy Students' Participation in a Research Experience Culminating in Journal Publication. Am J Pharm Edu. 2010;74(3):Article 47.

9. Plaza CM, Draugalis JR, Slack MK, Skrepnek GH, Sauer KA. Use of Reflective Portfolios in Health Sciences Education. Am J Pharm Edu. 2007;71(2): Article 34.

10. Surratt CK, Drennen JK III, Bricker JD. The "Research Track" concentration, a New PharmD elective option. Am J Pharm Edu. 2005; 69(5):Article 90

11. Vaidean GD, Vansal SS, Moore RJ, Feldman S. Student Scientific Inquiry in the Core Curriculum. Am J Pharm Edu 2013; 77 (8): Article 176. 